\title{
Systemic psychotherapy with families where someone has an autism spectrum condition
}

\author{
Sarah Helps \\ Tavistock Clinic, 120 Belsize Lane, London NW3 5BA, UK \\ Tel.: +44 208938 2240; E-mail: shelps@tavi-port.nhs.uk
}

\begin{abstract}
.
BACKGROUND: Families play an important role in facilitating the development and well-being of children with autism spectrum conditions.

OBJECTIVES: After setting the scene with a clinical example, and providing a brief discussion of the current thinking about the aetiology of Autism spectrum conditions, this paper provides a review of the literature regarding the practice of systemic psychotherapy with families in which a child has an autism spectrum condition (ASC).

METHODS: A search of databases and journals revealed a large number of opinion papers regarding how family therapists might work with families of children with ASCs and a smaller number of papers that describe or explore actual clinical practice.

RESULTS: Pilot studies using qualitative methods and practice-based evidence in the form of descriptions of clinical work offer a solid footing on which to develop systemic practice to help families where a person has an ASC.

CONCLUSION: Given the multifactorial nature of the aetiology of ASCs it is suggested that systemic interventions have the potential to influence changes at multiple levels of functioning for the child and the family.
\end{abstract}

Keywords: Autism spectrum condition, family therapy, systemic psychotherapy

\section{Setting the scene with a clinical example}

The Brown family (names and details have been changed to ensure confidentiality) is a two-parent white-British family with early teenage sons, Callum and David. Both parents work in professional jobs outside of the home. Callum and David and the family are not facing environmental or social stressors at the present time. One aspect of Callum's identity is the diagnosis of an autism spectrum condition (ASC). Like his parents and brother, he is an intellectually able young person, who is talented in specific ways, but who greatly struggles in social situations where he is unclear about what is expected of him. These difficulties have troubled him since he started school but it was not until he was eight years old that he received a diagnosis of, as was then known, Asperger's Syndrome. Each family member has a different idea about the cause of Callum's difficulties and whose 'problem' it is, although everyone including Callum believes that there is something 'wrong' with him. The family struggle to spend time all together as the parents find it difficult to understand why Callum reacts in particular ways to their encouragements to try new things and have new experiences. The family don't yet agree about what, and who, needs to change. Overall, the family is experiencing stress, distress and frustration, which causes great difficulty in each family dyad and across the whole family system. 
In joining with the family in conversation, I experience a constant sense of frustrated and missed relational connection. Each family member frequently makes engaging overtures to another but these seem to land or to be experienced in unintended ways. Warm, calm overtures quickly escalate into frustrated WHY WON'T YOU JUST angry verbal missiles, hurled around the room.

I sit with the family feeling very sad, not quite knowing how I might build a working therapeutic relationship with each person and with the family as a whole. My aim, through temporarily being 'with' the family in their discussions and disagreements, is to help them find different and more comfortable ways of being with each other and in going on in their conversations and daily lives.

As our conversations continue, I try to join with each family member and open a dialogue about the impact and meanings of this thing called Asperger's Syndrome (AS). I try to hold the diagnosis centrally but lightly, using my knowledge of ASCs to inform and guide but not to blind or constrain my questions.

Although people with ASCs present in unique ways, the struggles faced by this family are typical of those I see in my clinic.

\section{What are autism spectrum conditions?}

The answer to this question is complex and evolving. Ideas as to what autism 'is', have changed greatly since the term autism, and slightly later the term Asperger's Syndrome, were introduced in the 1940's. There is a lively debate within the critical psychiatry field as to whether 'autism' is even a meaningful diagnostic category (see Timimi, 2011). While these debates are very important, they will not be addressed in this paper.

According to current diagnostic criteria, Autism Disorders are lifelong neurodevelopmental conditions, which range in severity but which significantly impair everyday functioning with deficits in two core domains. These are: persistent deficits in social communication and social interaction across multiple contexts, and restricted, repetitive patterns of behavior, interests, or activities (APA, 2013).

A brief word on language. While the diagnostic label used by the DSM-5 is Autism Spectrum Disorder, Autism Spectrum Condition (ASC), is the term coined by Baron-Cohen among others (2009) to reflect the notion that not all symptoms of the condition reflect disorder. While many of the symptoms associated with an ASC can be deeply troubling and impairing, some aspects can be helpful, enjoyable and are to be celebrated. Indeed in his recent book outlining the history of the condition, Silberman highlights how the world would be a much poorer place, in all kinds of ways, had people who think 'differently' not achieved what they have. (Silberman, 2015).

Prevalence rates sit at around 1\% (Baron-Cohen et al., 2009). Around $80 \%$ of people who are diagnosed with an ASC have average or above average cognitive ability. More males than females are diagnosed and while this may reflect aspects of the condition it may also reflect the ways in which the condition is diagnosed in the context of society's differing expectations of men's and women's social skills (Mandy et al., 2012; Shefcyk, 2015).

People with ASCs are more likely than those without ASCs to experience a range of psychological/mental health difficulties as they struggle to negotiate the social world, and therefore people with ASCs, across the lifespan, are more likely to seek access to psychological well-being/mental health services. Hundreds of papers have highlighted the stresses, strains and joys experienced by parents of children with an ASC and the ways in which families attempt to manage the challenges of parenting a child who has social communication differences.

Thousands of papers have been published which try to explicate the causes of ASCs. A current, widely held view is that there is a multifactorial basis to ASC which includes a polygenetic, neurobiological and developmental basis (Minshew \& Williams, 2007). Much research over many years has tried to find a 'home' in the brain for ASCs and the difficulty of doing so may be because either there is no straightforward neurological home, or because not enough is currently understood about the brain as a tightly interconnected system (Cozolino, 2014) so as to be able to formulate how a condition with such a wide range of symptoms can arise.

Influenced by Bronfenbrenner's social ecological model (Bronfenbrenner, 1979) together with a reading of some of the neuroscientific literature (see Celano, 2013) it is increasingly accepted that social and environmental factors exacerbate or suppress the expression of those genetic and neurobiological factors which give rise to the features of ASC. The development of all human beings is influenced both by genetic, social and environmental factors so it cannot be any different for people who with a diagnosis of an ASC (see Fig. 1). 


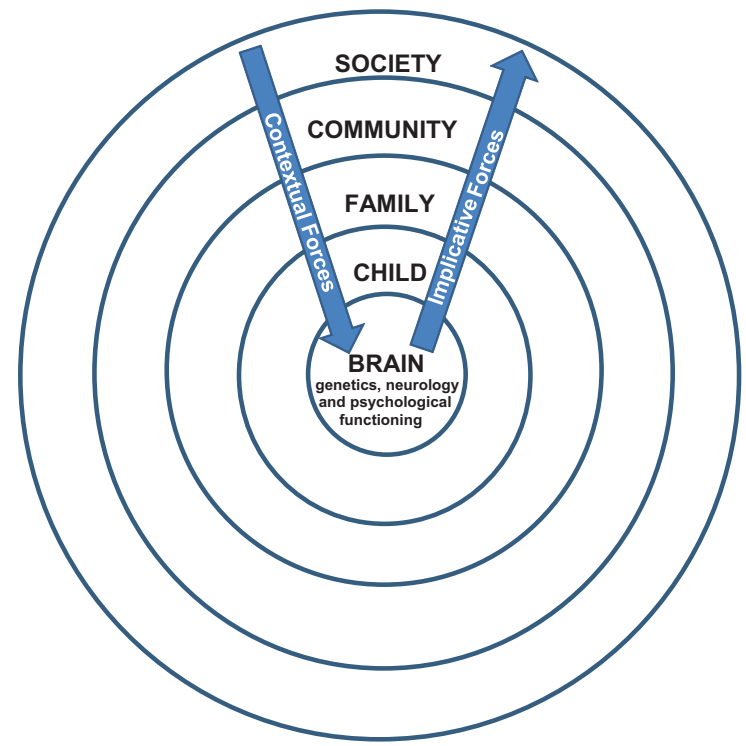

Fig. 1. The way in which the child's brain 'works', (the brain itself being influenced by a variety of intrinsic and extrinsic factors), affects all aspects of the child's functioning. Over time, both implicative and contextual forces create a bi-directional relationship between brain, child, and the environment of the family, the broader community and society. This biopsychosocial framework demonstates that each level of functioning needs to be understood, and can be influenced, by all other levels. After Bronfenbrenner (1979), Gutstein (2009), Crittenden et al. (2014) and Cronen (1994). Factors within the child lead to a relational dance that becomes increasingly mis-attuned. This mis-attunement then affects and is affected by the wider context and unusual patterns of interaction and behaviour becomes increasingly fixed. Contextual factors are those that impact from the broader context down towards the child. Implicative factors are those that ripple out from the child to the family and to the wider context.

Crittenden et al.'s position (2014) is helpful to systemic practitioners, whereby they suggest that genetic, neurological, psychological, relational and contextual factors may all coalesce to yield the range of symptoms currently associated with a diagnosis of ASC.

Accepting this multifactorial aetiology in which social factors are in part involved in the development of the condition does not in any way suggest that parents are to blame for their children's difficulties. Early practitioners suggested that mothers 'caused' their children's autism by their emotionally distant and cold nature (Kanner, 1944; Bettelheim, 1967). Such ideas were quickly rejected by the scientific community but seem to have had the effect of at least temporarily delaying the development of helpful and constructive practices to support families in promoting their children's development.

Therefore, if both intrinsic and extrinsic processes lead to patterns of communication and behaviour commensurate with an ASC, if relationships can influence the way the brain is 'built' especially in the very early years (e.g. Siegel, 2012) and if the brain is particularly plastic in its first couple of decades, then there gives rise to the possibility for intervention to produce change, not only at the level of relationship, action and meaning but also, at the level of neural connectivity.

The process of relational mis-attunement is thought to start early, as a parent or carer tries to relate to an infant with an atypical neurodevelopmental profile who responds in unexpected ways. As time goes on, parents try to act in more extreme, directive ways in order to try and build a relationship with their children (Hobson, 2004; Gutstein, 2009; Crittenden et al., 2012). So, if the relational dance between child and carer can be revisited and somehow reset, or if 'ordinary' parent-infant interactions can be promoted (Wan et al., 2013; Green et al., 2015), then it might be possible to build social communication in a more ordinary way. By 'ordinary' it is not implied that there is a 'right' or normative way to do social communication but that it is possible to build ways of relating that feel more comfortable and emotionally connected for the child with ASC and their family.

The ideas developed above are particularly attractive to systemic practitioners as they suggest that though therapeutic, relational work, it might be possible to help the parent-and-child, and the family, repair uncomfortable patterns of interacting and develop communicative patterns that feel more socially connected for all involved. 


\section{Systemic psychotherapy with people with autism spectrum conditions}

Family and systemic psychotherapy is increasingly found to be effective at helping relieve both individual and relationship distress. Given that the aim of family therapy is, in its broadest terms, to help people relate more easily with each other, and given that ASCs are essentially a problem of social communication and relating, there is great scope for family therapists to work with people of all ages who have ASCs and their relational networks.

NICE guidelines for working with children with ASCs recommend psychosocial interventions to treat the core features of autism (CG128, 2014). They specify interventions that increase parents', carers', teachers' or peers' understanding of, and sensitivity and responsiveness to, the child or young person's patterns of communication and interaction.

NICE guidelines for adults also recommend psychosocial interventions to remediate the core features of autism. The focus of the adult guidelines is on behavioural/social learning interventions, which have modeling, decision-making and teaching social rules as a focus (CG142, 2012).

While family therapy is not specifically recommended within the NICE guidelines, the targets for intervention, as described above, are clearly commensurate with systemic interventions.

Some thirty years ago, Harris clearly called for a systemic perspective in working with families of children with autism, and highlighted how attention should be paid to the family context and to the impact of any intervention on the family (Harris, 1983, 1984). This call has slowly been taken up and described in the literature.

\section{Contemporary systemic psychotherapy}

Contemporary systemic psychotherapists (also known as family therapists) regard families as experts in and on their own lives. Systemic practice holds problems as relational rather than intrinsic to one member of a system, without denying that each part of a system/each family member brings their own unique pattern of strengths and challenges (Dallos \& Draper, 2010).

Systemic psychotherapists are usually curious about the psychiatric diagnostic labels which families bring with them to the therapeutic conversation. Family therapists, especially those who subscribe to a social constructionist or critical realist ontology, typically work to deconstruct the meaning of THIS label to THIS person in THIS family and THIS point in the life cycle (Brown, 1995; Wilson, 2013; Helps, 2016) and to open up possibilities of acting and relating that may have become closed down by assumptions and beliefs connected to the diagnostic label.

\section{What do family therapists do with families where there is someone with ASC?}

There are a wealth of discussion articles regarding how family therapists might be useful to families where there is ASC, but few papers have been published regarding what actually goes on in practice. No systematic review of the current literature has been published. This paper provides a systematic literature review of both opinion and research in this field.

\subsection{What might family therapists do with families where there is ASC?}

In his round-up of interventions that family therapists could provide to families where there is ASC, (Bradford, 2010a, b), Bradford suggested that family therapists could help by providing education about the condition, by guiding families to additional educational resources and in navigating the professional systems involved with their child. He suggested that family therapy sessions might involve work on social and communication skills, mood disorders and repetitive routines by improving adaptive behaviours, and might involve providing therapy to family members regarding the grief and confusion of the diagnosis and of living with a child with a life-long disability. $\mathrm{He}$ recommended providing help for the affected child to understand theircondition and support for siblings too.

In a similar vein, Solomon and Chung (2012) described the importance of a tripartite approach to intervention, involving traditional therapies, biomedical therapies and emotional support for the family. They suggested that family therapists might be one member of a multi-disciplinary team and might take on advocacy, therapeutic and psychoeducative roles.

Neely et al. (2012) published another description of the ways in which therapists could help families where there is ASC. They suggested that therapists could contribute in facilitating the family to grieve the loss of the 'neurotypical' child, exploring which of the huge range of available interventions might fit for the family, serving as a coach/mediator, exploring 
emotions, feelings and belief systems and affirming family competence and strengths. They concluded by highlighting the importance of keeping the family's social and cultural context in mind and in staying alert to and reflecting on how one's own beliefs, biases and assumptions might influence the work.

Helps and Sheppard (2015) highlighted the importance of working with parents of young children who are at risk for the development of ASCs or who have received a very early diagnosis.

Finally, Goepfert et al. (2015) reviewed a range of family therapy literature and concluded that "multiple schools of family therapy theory may be applied to this population, with strategic, narrative, and structural interventions offering approaches that may be particularly suited to the challenges typically faced by children with ASDs and their families" p581.

Therefore, all these reviews and opinion pieces highlight the possible benefits of family therapy intervention to families where there is someone with ASC.

\subsection{What do family therapists do with families where there is ASC?}

Stoddart (1999) described three pieces of clinical work that involved a combination of individual and family therapy with adolescent boys with a diagnosis of Asperger's Syndrome and their families. He described how families needed different things at different times and that who was involved in each therapeutic conversation was determined by who was involved in the problem or goal. He located his systemic work primarily within a structural frame where the aim of the work was to clarify and establish relational hierarchies, boundaries and subsystems to enable the family to complete their developmental tasks. He also argued for theoretical flexibility according to the needs of the family at any point in time.

Simon (2004) gave a detailed description of systemic practice with a child and family with Asperger's Syndrome. She outlined a six-session systemic intervention, developed as part of her work in a CAMHs family therapy team. Families were offered six sessions and one follow-up appointment. The first session involved setting the context for the sessions, going over the programme of work and creating a working relationship with the family. The second involved discussion about family about communication patterns and identified what the family wanted to change. Session three was devoted to learning about the special interests of the child and finding ways to use the expertise of the child. Simon described how in these sessions, the family therapy team paid particular attention to rule-bound or rule-creating systems, patterns of change, power relations, roles of individuals, alliances, communication patterns and decision-making.

Sessions four and five explored links between the child's special interests and the family relationships. In session six, issues were drawn together and other family dynamics and issues were raised. In the final session, video material was shown to parents to collaboratively review the progress of the work.

While their intervention was not formally evaluated, Simon commented on how families reported that the sessions had made a positive difference and she noted a frequent request for further sessions to explore parenting and parental relationships, alongside the family relationship to the diagnosis of Asperger Syndrome.

In a similar vein (Tilsen et al., 2005), Tilsen described her narrative therapeutic work with a young person with Asperger's Syndrome named Michael and his mother. She described how she explored the helpful things about the ways in which Michael thought and described a process of "consulting Michael in order to generate an understanding of his experiences" (p35) which enabled her to understand him in a much clearer way than she could, had she reduced his experience to a mental health diagnosis. She then used the narrative practice of externalizing to help Michael address not Asperger's Syndrome but "unnimbleness", his description for the struggles in thinking that he experienced. She described how Michael used his knowledge of electricity to help him in explaining and finding ways through the challenges he faced.

Tilsen ended by offering some reflections on how she had resisted "the dominant discourse of expertness" to conduct the work with Michael and his mother, "removing preconceived, expert ideas from the therapeutic conversation creates space for client voices to reach therapists' ears" (p41).

After publishing an opinion piece on how narrative therapy might be helpful to young people with ASCs (Cashin, 2008), Cashin et al. (2013) reported a pilot study of brief narrative therapy with 10 young people with autism of five sessions over 10 weeks. Sessions involved getting to know the person away from the problem and identifying a preferred reality, externalizing the problem (that is separating the 'problem' from the person), and doing experiments to create new meanings and relationships to the problem. Based on positive data trends from a variety of out- 
come measures, Cashin et al. concluded that narrative therapy had merit as an intervention with young people with autism. In the only description of work with parents and young children, Olinger (2010) described using narrative approaches in extending her work with parents as part of a play-group that their children with ASCs attended. She worked collaboratively with parents, which involved asking parents to observe the play room session and then to talk to each other about what they had seen in front of a therapist. She then described running a 'parent night' where parents talked and others took an outsider-witness position. This culminated in an open document written by parents summarizing their experiences.

On the basis of a pilot study, Ramisch (2013) concluded that a ten-week Emotion Focused Therapy (EFT) home-based intervention could be of particular use with families as a way to "move beyond negative interaction cycles and place their responses within a more emotionally supportive frame" (p. 386). She suggested some adaptations to EFT, including working in the family home; going slowly in the initial phases of the work to identify problematic interactional cycles and adjusting the number of sessions to fit the pace of the couple; abandoning preconceived ideas about how couples of children with ASC might communicate and not loading all couple difficulties on to the presence of a child with ASC.

Helps (2016) described how she adapted core systemic practices in working with young women with ASC and their families. Adaptations involved using knowledge about ASCs and how it affects children and their families, and using this in psychoeducative conversations. Adaptations also involved changing the pace of the work and going slowly to catch, understand and process emotion and meaning in what is being communicated. Inner dialogue (the thoughts going through a therapist's mind as the session unfolds) were used in a transparent way to model the complexities of inner and outer thought and to model how one might monitor and use feedback in talk-in-interaction. Restricted interests and behaviours were used as a starting point from which to explore increased flexibility of interests and actions.

\section{Summary and suggestions for future research}

The needs and development of one family member recursively and bi-directionally affect and are affected by the needs and development of another family member (Fig. 1). This applies to families where children (whatever their age) follow an ordinary developmental course and to families where children's development takes a different path (Cridland et al., 2014; Helps, 2016). Family therapists are well placed to work with families where relationships and patterns of communication have gone awry, whatever has caused this. The extant literature shows how systemic therapists have described and how they have started to test out what works in working with families where there is ASC.

Going back to Callum and his family, the review of the literature shows how family therapists might work therapeutically with Callum and his family to address these difficulties. Therapeutic work needs to involve working with different parts of the family system at different times. Therapeutic conversations will move between fact and meaning and will focus in and out, to consider the child, the family, and the family in context.

Based on the published literature, this systematic review covers the small but important body of practice-based evidence about what works in working with families where there is a child or young person with ASC. It is clear that systemic, narrative approaches hold promise for families where a person has ASC. These interventions work to open up possibilities of thinking, being and relating that have previously become closed down by ASC.

There are no large randomised controlled trials that have explored and evaluated whether and how family therapy 'works' with people with ASCs and their families. While the academic scientific community might appreciate such studies, they are perhaps not so important as are small-scale qualitative descriptions of process and practice, which can guide and inform contemporary systemic practice. Personal reflections on practice together with small scale, qualitative studies exploring aspects of practice may provide the greatest resonance for practitioners who want to reflect on and develop their knowledge and skills. Following Neely et al. (2012) more practice-based evidence that highlights the reflexive processes of the therapist as contributing to the work would be of benefit (e.g. Evans et al., 2014).

Following the call by Carr (2010) to family therapy researchers in general, further research is required regarding what works, for whom and how. Specific to families where there is a person with ASC, there is much to be done. All future research would benefit from consideration of the intersections of the 
Social GRRAACCEESS (Burnham, 1992, 2012) to paint a fuller picture of the complexities of family life when bringing up a child who requires different kinds of parenting. Such attention might help researchers make sense of why children with very similar presentations can make such different progress (Seal, 2013).

Further research which develops extant narrative practices on how exploring the meaning of the condition to the child and family would be of benefit. Studies exploring the progress and outcomes of therapeutic work with parents who themselves have ASC or with families where there are very young or grownup children with ASC are welcomed. Research which explores contemporary systemic practices such as the use of social-constructionist, dialogical approaches, and the tools of therapeutic letters, the one-way screen or the reflecting team would also be illuminating. Finally, research that attends to processes within therapeutic work, such as the therapeutic alliance and embodied, non-verbal aspects of systemic practice will also be helpful to practitioners.

ASCs can be seen, at a neurological level, as a problem of interconnectivity (Minshew et al., 2007; Maximo et al., 2014). It is an exciting heuristic to consider the parallels between problems with connectivity at the level of the brain and connectivity in social relationships. While caution is required in making claims about the evidence regarding links between changes at the level of the brain linked to therapeutic work (Dawson et al., 2012; Celano, 2012) in time, it might be possible to track the bidirectional impact of systemic work at all levels of the biopsychosocial ecological model, not only on communication, beliefs, actions and relationships but also on the neural connections that are made as a result of having conversations that enhance the process of social communication.

\section{References}

American Psychiatric Association Diagnostic and Statistical Manual of Mental Disorders. 5th ed. Washington, DC: American Psychiatric Association; 2013

Baron-Cohen, S., Scott, F. J., Allison, C., Williams, J., Bolton, P., Matthews, F. E., \& Brayne, C. (2009). Prevalence of autismspectrum conditions: UK school-based population study. The British Journal of Psychiatry, 194(6), 500-509.

Bettelheim, B. (1967). The Empty Fortress. New York.

Bradford, K. (2010). Brief education about autism spectrum disorders for family therapists. Journal of Family Psychotherapy, 21(3), 161-179.
Bradford, K. (2010). Supporting families dealing with Autism and Asperger's Syndrome. Journal of Family Psychotherapy, 21, 149-156.

Bronfenbrenner, U. (1979). The ecology of human development: Experiments by design and nature.

Burnham, J. (1992). Approach-method-technique: Making distinctions and creating connections. Human Systems, 3(1), 3-26.

Burnham, J. (2012). Developments in the social GRRRAAACCEEESSS: Visible-invisible and voiced-unvoiced. In I.-B. Krause (ed.) Culture and Reflexivity in Systemic Psychotherapy. Mutual Perspectives (pp. 139-160). London: Karnac

Carr, A. (2010). Ten research questions for family therapy. Australian and New Zealand Journal of Family Therapy, 31(2), 119-132.

Cashin, A. (2008). Narrative therapy: A psychotherapeutic approach in the treatment of adolescents with Asperger's disorder. Journal of Child and Adolescent Psychiatric Nursing, 21(1), 48-56.

Cashin, A., Browne, G., Bradbury, J., \& Mulder, A. (2013). The effectiveness of narrative therapy with young people with autism. Journal of Child and Adolescent Psychiatric Nursing, 26(1), 32-41.

Celano, M. P. (2013). Family psychology in the age of neuroscience: Implications for training. Couple and Family Psychology: Research and Practice, 2(2), 124.

Cridland, E. K., Jones, S. C., Magee, C. A., \& Caputi, P. (2014). Family-focused autism spectrum disorder research: A review of the utility of family systems approaches. Autism, 18(3), 213222.

Crittenden, P. M., Dallos, R., Landini, A., \& Kozlowska, K. (2014). Attachment and Family Therapy. McGraw-Hill Education (UK).

Cronen, V. E. (1994). Coordinated management of meaning: Practical theory for the complexities and contradictions of everyday life. The Status of Common Sense in Psychology. J. Siegfried, Ed. (pp. 183-207). Norwood, NJ: Ablex Press.

Cozolino, L. (2014). The Neuroscience of Human Relationships: Attachment and the Developing Social Brain (Norton Series on Interpersonal Neurobiology). WW Norton \& Company.

Dallos, R., \& Draper, R. (2010). An introduction to family therapy: Systemic theory and practice. McGraw-Hill Education (UK).

Dawson, G., Jones, E. J., Merkle, K., Venema, K., Lowy, R., Faja, S., et al. (2012). Early behavioral intervention is associated with normalized brain activity in young children with autism. Journal of the American Academy of Child \& Adolescent Psychiatry, 51(11), 1150-1159.

Evans M. (2014). Mum's the word - reflections on how our own experiences can influence our therapeutic encounters and how we can continue to explore difference when our stories appear to be the same, Context, 135, 18-20

Goepfert, E., Mulé, C., von Hahn, E., Visco, Z., \& Siegel, M. (2015). Family system interventions for families of children with autism spectrum disorder. Child and adolescent psychiatric clinics of North America, 24(3), 571-583.

Gutstein, S. E. (2009). Empowering families through relationship development intervention: An important part of the biopsychosocial management of autism spectrum disorders. Ann Clin Psychiatry, 21(3), 174-82.

Harris, S. L. (1983). A family systems approach to behavioral training with parents of autistic children. Child \& Family Behavior Therapy, 4(1), 21-35. 
Harris, S. L. (1984). The family and the autistic child: A behavioral perspective. Family relations, 127-134.

Helps, S., \& Sheppard, N. (2015). Developing ways of working with parents and their infants to improve the core deficits of autism, International Journal of Birth and Parenting Education, 2(3), 26-30

Helps, S. L. (2016). How some systemic practices might help young women with Autism Spectrum Conditions and their families, Context, April 2016 XX awaiting page no.

Hobson, P. (2004). The cradle of thought: Exploring the origins of thinking. Pan Macmillan.

Kanner, L. (1944). Early infantile autism. The Journal of Pediatrics, 25(3), 211-217.

Mandy, W., Chilvers, R., Chowdhury, U., Salter, G., Seigal, A., $\&$ Skuse, D. (2012). Sex differences in autism spectrum disorder: Evidence from a large sample of children and adolescents. Journal of Autism and Developmental Disorders, 42(7), 13041313.

Maximo, J. O., Cadena, E. J., \& Kana, R. K. (2014). The implications of brain connectivity in the neuropsychology of autism. Neuropsychology Review, 24(1), 16-31.

Minshew, N. J., \& Williams, D. L. (2007). The new neurobiology of autism: Cortex, connectivity, and neuronal organization. Archives of Neurology, 64(7), 945-950

Neely, J., Amatea, E. S., Echevarria-Doan, S., \& Tannen, T. (2012). Working with families living with autism: Potential contributions of marriage and family therapists. Journal of Marital and Family Therapy, 38(s1), 211-226.

NICE Guideline 128 Autism diagnosis in children and young people (2011). retrieved from: http://www.nice.org. uk/guidance/cg128/resources/guidance-autism-diagnosis-inchildren-and-young-people-pdf

NICE Guideline 142, Autism: Recognition, referral, diagnosis and management of adults on the autism spectrum, retrieved from http://www.nice.org.uk/guidance/cg142

Olinger, C. (2010). Privileging insider-knowledges in the world of autism. International Journal of Narrative Therapy \& Community Work, 2010(2), 37.
Ramisch, J. L., Timm, T. M., Hock, R. M., \& Topor, J. A. (2013). Experiences delivering a marital intervention for couples with children with autism spectrum disorder. The American Journal of Family Therapy, 41(5), 376-388.

Seal, A. (2013). Health, disability and functioning, p3-10. In Arnab Seal, Gillian Robinson, Anne M Kelly and Jane Williams (eds), Children with Neurodevelopmental Disabilities: The essential guide to assessment and management, (pp3-10), London, Mac Keith Press

Shefcyk, A. (2015). Count us in: Addressing gender disparities in autism research. Autism, 19(2), 131-132.

Siegel, D. J. (2012). Pocket Guide to Interpersonal Neurobiology: An Integrative Handbook of the Mind (Norton Series on Interpersonal Neurobiology). WW Norton \& Company.

Silberman, S. (2015). NeuroTribes: The legacy of autism and how to think smarter about people who think differently. Allen \& Unwin.

Simon, G. (2004). Systemic family therapy with families with a child who has a diagnosis of asperger syndrome. Human Systems: The Journal of Systemic Consultation and Management, 15(4), 257-274.

Solomon, A. H., \& Chung, B. (2012). Understanding autism: How family therapists can support parents of children with autism spectrum disorders. Family process, 51(2), 250-264.

Stoddart, K. P. (1999). Adolescents with Asperger Syndrome Three Case Studies of Individual and Family Therapy. Autism, 3(3), 255-271.

Tilsen, J., Russell, S., \& Nylund, D. (2005). Nimble and courageous acts: How Michael became the boss of himself. Journal of Systemic Therapies, 24(2), 29-42.

Timimi, S. (2011). Autism is not a scientifically valid or clinically useful diagnosis. BMJ, 343.

Wan, M. W., Green, J., Elsabbagh, M., Johnson, M., Charman, T., \& Plummer, F. (2012). Parent-infant interaction in infant siblings at risk of autism. Research in Developmental Disabilities, 33(3), 924-932. 